\title{
Combined Use of Caesium-137 Re- sampling Approach and Excess Lead- 210 Sediment Dating to Assess The Impacts of Climate Change and Agricultural Practices on Soil Erosion and Sedimentation in Northwest Morocco
}

\author{
MERYEM MOUSTAKIM ${ }^{1}$, MONCEF BENMANSOUR ${ }^{2}$, \\ ASMAE NOUIRA $^{2}$, AZOUZ BENKDAD ${ }^{2}$ AND BRAHIM \\ DAMNATI $^{3}$ \\ ${ }^{1}$ Faculty of Sciences and Techniques of Tangier \\ ${ }^{2}$ Centre National de l'Energie, des Sciences et des Techniques \\ Nucléaires \\ ${ }^{3}$ Faculty of Sciences and Techniques \\ Presenting Author: moustmeryem@gmail.com
}

Water erosion has seriously threatened the sustainability of soil resources and water reservoirs in Northwest Morocco. Climate change and land use are among the main factors that trigger the situation in the area. This study aims to evaluate changes in soil erosion and sedimentation in the Northwest region based on the use of the Caesium-137 re-sampling approach in five upland agrosystems for the periods 1954-2000 (or 2001, 2002) and 1954-2017 (or 2018) and excess Lead-210 was used to estimate the temporal variations of the sedimentation rate in the "9th of April 1947" dam located in the region.

The results show that soil loss rates had decreased from 36 to 29 t.ha ${ }^{-1} \cdot \mathrm{yr}^{-1}$ within Nakhla field due to the beneficial impact of agricultural practices and the implemented soil erosion control strategy, based on more frequent fallow with natural vegetation and olive plantations. This decrease is consistent with the available records of sediment yield in the Nakhla dam during the studied periods. In El Hachef watershed, the results show that soil erosion rates had decreased in the two studied fields from

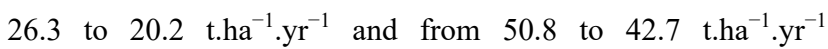
respectively due to the frequent fallows and the regional crop rotation. Similar evidence of decrease in soil loss from 19.4 to $16.1 \mathrm{t}^{-h^{-1}} \cdot \mathrm{yr}^{-1}$ was recorded in a field within Raouz watershed, whereas soil erosion rates had increased from 4.5 to 5.7 t.ha ${ }^{-1} \cdot \mathrm{yr}^{-1}$ in the other field where agricultural practices were not changed. This variation represents an increase of the soil erosion rate of about $26 \%$ between the two periods and could be due to climate change impact on soil erosion in this area. In El Hachef dam, an increase of the mean sedimentation rate of around $30 \%$ was also observed between the periods 1950-2002 and 19502015, which can be attributed to the combined impacts of climate change and intensive agriculture in some fields in the region.

The results of this study proved the effectiveness of the fallout radionuclides approach in assessing the impacts of climate change and agricultural practices on soil erosion and sedimentation in Northwest Morocco. 